\title{
A Study on the Microbiology of Chronic Suppurative Otitis Media in a Tertiary Care Hospital in South India
}

\author{
Dr. Manaswini Das ${ }^{1 *}$, Dr. Deeganta Mohanty ${ }^{2}$, Dr. U Sreenivasa Rao ${ }^{3}$ \\ ${ }^{1}$ Associate Professor, Department of Microbiology, ASRAM Medical College, Eluru-534005, Andhra Pradesh, India \\ ${ }^{2}$ Professor, Department of ENT, ASRAM Medical College, Eluru-534005, Andhra Pradesh, India \\ ${ }^{3}$ Professor and Head, Department of Microbiology, ASRAM Medical College, Eluru-534005, Andhra Pradesh, India
}

DOI: $\underline{10.36348 / \text { sjpm.2020.v05i09.002 }}$

| Received: 03.09.2020 | Accepted: 10.09.2020 | Published: 17.09.2020

*Corresponding author: Dr. Manaswini Das

\section{Abstract}

Chronic suppurative otitis media (CSOM) is an important cause of morbidity in developing countries and a harbinger of many complications, out of which hearing loss; especially in children is a cause for concern. The present study focuses on the causative agents of CSOM and their antibiotic susceptibilities. The patients were found to be more in the first two decades of life (29.2\%) and Pseudomonas aeruginosa was found to be the most common agent (49.7\%) followed by Staphylococcus aureus $(23.8 \%)$. The isolates were found to be susceptible to a number of antibiotics, which can be used to prevent the life-long complications of CSOM. Timely culture and sensitivity helps in the management of these cases.

Keywords: CSOM, Hearing loss, Pseudomonas aeruginosa.

Copyright @ 2020: This is an open-access article distributed under the terms of the Creative Commons Attribution license which permits unrestricted use, distribution, and reproduction in any medium for non-commercial use (NonCommercial, or CC-BY-NC) provided the original author and sources are credited.

\section{INTRODUCTION}

Chronic suppurative otitis media (CSOM) is defined as chronic inflammation of middle ear and mastoid cavity that usually presents with recurrent ear discharges or otorrhoea through a tympanic perforation $^{1}$. Incidence of this disease is higher in developing countries, especially among people in the lower socio-economic strata, which may be due to reasons like malnutrition, overcrowding, poor hygiene, inadequate health care, and recurrent upper respiratory tract infection [2].

CSOM is classified into two types, tubotympanic and attico-antral depending on whether the disease process affects the pars tensa or pars flaccida of the tympanic membrane (TM) [2]. Tubotympanic is called as a 'safe' type or 'benign' type as there are less severe complications whereas, atticoantral is the 'unsafe' or 'dangerous' type as it is more frequently associated with more complications and may be life threatening at times [3]. Infection can spread from the middle-ear to vital structures such as the mastoid, facial nerve, labyrinth, lateral sinus, meninges and brain leading to mastoid abscess, facial nerve, paralysis, deafness, lateral sinus thrombosis, meningitis and intracranial abscess $[4,5]$. Of all the complications, hearing loss associated with chronic ear discharge is nearly always significant, reported in $50 \%$ of cases and tending to be more severe than those reported in other types of otitis media [6]. Antibiotics have been frequently misused and this has led to the emergence of multi-drug resistant bacterial strains and disease complications [7].

The prevalence and antibiogram of the causative organisms has been reported to vary with time and geographical locations as well as with different patient populations. The prevalence of the causative agents of CSOM and their antimicrobial susceptibility pattern should be known in order to effectively manage the patients and prevent complications in the future.

The aim of this cross-sectional study was to determine the microbiological causes of CSOM in patients attending our hospital, along with the antibiotic sensitivities of the bacterial isolates.

\section{MATERIALS AND METHODS}

This cross-sectional, retrospective study was performed at Alluri Sitarama Raju Academy of Medical Sciences, a tertiary care hospital in the West Godavari district of Andhra Pradesh, India. The study was performed in the Departments of Microbiology and ENT, and data was collected from the records of three months, from October to December, 2019. 
Swabs were collected from patients who were clinically diagnosed with CSOM, after obtaining appropriate consent. The patients who had not been on antimicrobial therapy for the last 7 days (topical or systemic) were included in the study.

The swabs were plated on blood agar, MacConkey agar, chocolate agar and Sabouraud's dextrose agar (SDA). Gram stain and $\mathrm{KOH}$ mounts were performed from smears of the swabs. The plates were inoculated at $37^{\circ} \mathrm{C}$ for 48 hours and the SDA slants were incubated at room temperature.

The isolates were identified by standard procedures. Antimicrobial sensitivity testing was performed by Kirby Bauer disc diffusion method on Mueller Hinton agar using standard CLSI guidelines.

All dehydrated media, reagents and antibiotic discs were procured from Hi-media Laboratories Pvt. Ltd., Mumbai, India.

\section{STATISTICAL ANALYSIS}

The data was analyzed by using Statistical Package for Social Sciences (SPSS) version 23.0 (trial version) and the prevalence of organisms was determined and expressed in percentage.

\section{RESULTS}

Out of a total of 170 swabs processed microbial growth was seen in $158(92.9 \%)$ and $12(7 \%)$ showed no growth. In $130(76.5 \%)$ the samples showed monomicrobial growth whereas in $28(16.5 \%)$ there was polymicrobial growth. Females $(58.8 \%)$ were more commonly affected than males. The age group of 11-20 years was slightly more affected $(21.7 \%)$ than the other age groups. Table 1 shows the age-wise distribution of different isolates from the cases of CSOM. The bacterial isolates were found to be as in Table 2 in an aerobic atmosphere. Candida species were found in 18 cases. Table 3 shows the antibiotic sensitivity pattern of bacterial isolates from CSOM cases.

Table-1: Age-wise distribution of different isolates from the cases of CSOM

\begin{tabular}{|l|l|l|l|l|}
\hline Age Group & Monomicrobial Isolates & Polymicrobial Isolates & Sterile & Total \\
\hline $0-10$ & 24 & 3 & 2 & 29 \\
\hline $11-20$ & 30 & 6 & 1 & 37 \\
\hline $21-30$ & 16 & 9 & 4 & 29 \\
\hline $31-40$ & 23 & 3 & 0 & 26 \\
\hline $41-50$ & 17 & 2 & 3 & 22 \\
\hline $51-60$ & 13 & 1 & 2 & 16 \\
\hline $61-70$ & 4 & 2 & 0 & 6 \\
\hline $71-80$ & 3 & 2 & 0 & 5 \\
\hline Total & $\mathbf{1 3 0}$ & $\mathbf{2 8}$ & $\mathbf{1 2}$ & $\mathbf{1 7 0}$ \\
\hline
\end{tabular}

Table-2: Bacterial isolates from cases of CSOM

\begin{tabular}{|l|l|}
\hline Staphylococcus aureus & 43 \\
\hline Coagulase Negative Staphylococci (CONS) & 18 \\
\hline Pseudomonas aeruginosa & 90 \\
\hline Escherichia coli & 12 \\
\hline Klebsiella pneumoniae & 11 \\
\hline Proteus mirabilis & 5 \\
\hline Acinetobacter baumanii & 2 \\
\hline Total & $\mathbf{1 8 1}$ \\
\hline
\end{tabular}

Table-3: Antibiotic sensitivity pattern of bacterial isolates from CSOM

\begin{tabular}{|l|l|l|l|l|l|l|l|l|}
\hline Bacterial Isolates & Amp & AC & Gen & AK & CTX & CoT & Cip & Pip \\
\hline Staphylococcus aureus & 38 & 40 & 41 & 39 & 42 & 30 & 29 & NA \\
\hline CONS & 10 & 18 & 15 & 16 & 18 & 15 & 16 & NA \\
\hline Pseudomonas aeruginosa & 83 & 88 & 88 & 85 & 80 & 59 & 63 & 90 \\
\hline Escherichia coli & 9 & 11 & 12 & 12 & 11 & 9 & 10 & NA \\
\hline Klebsiella pneumoniae & 3 & 10 & 9 & 11 & 12 & 6 & 9 & NA \\
\hline Proteus mirabilis & 2 & 4 & 5 & 5 & 4 & 4 & 5 & NA \\
\hline Acinetobacter baumanii & 1 & 1 & 2 & 2 & 2 & 0 & 1 & NA \\
\hline Total & $\mathbf{1 4 6}$ & $\mathbf{1 7 2}$ & $\mathbf{1 7 2}$ & $\mathbf{1 7 0}$ & $\mathbf{1 6 9}$ & $\mathbf{1 2 3}$ & $\mathbf{1 3 3}$ & $\mathbf{9 0}$ \\
\hline
\end{tabular}

Amp: Ampicillin; AC: Amoxycillin-Clavulanic acid; Gen: Gentamicin; AK: Amikacin; CoT: Cotrimoxazole; Cip: Ciprofloxacin; Pip: Piperacillin 


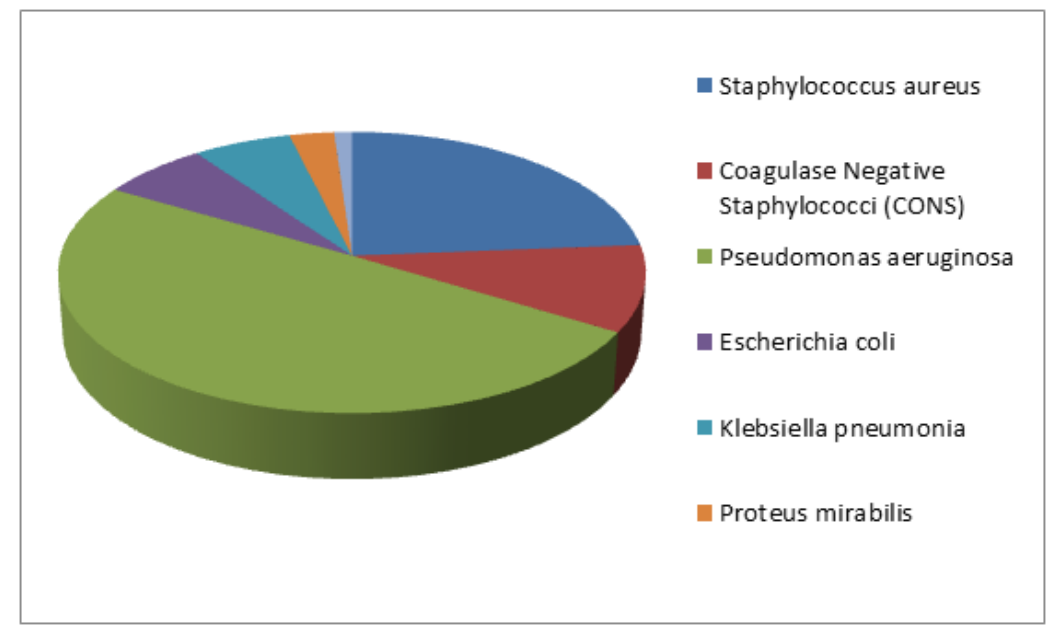

Plate-1: Distribution of bacterial isolates in CSOM

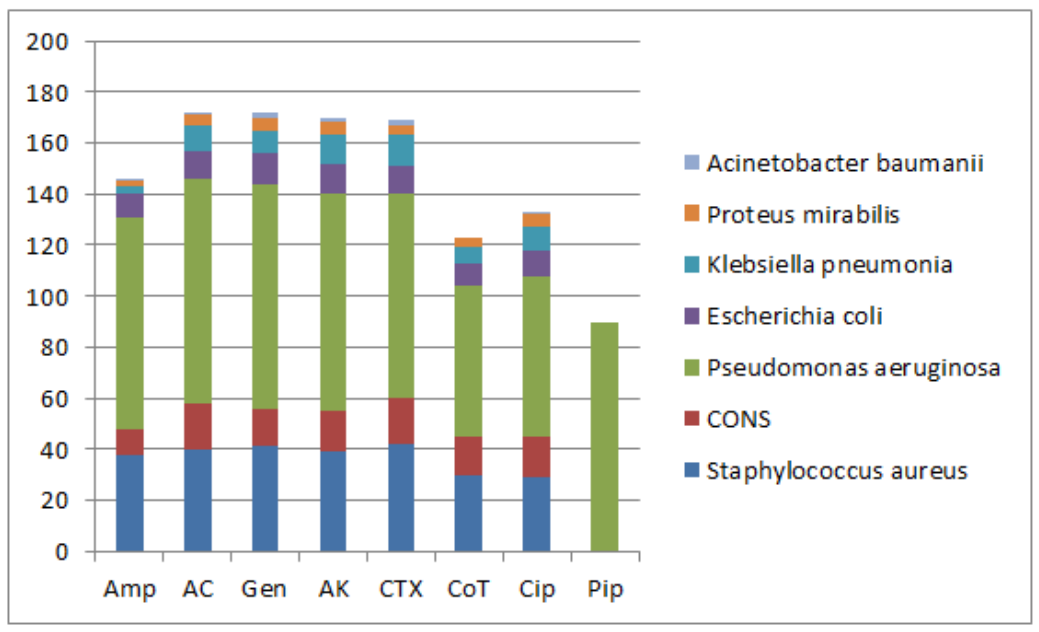

Plate-2: Sensitivity Pattern of isolates from cases of CSOM

\section{DISCUSSION}

Chronic suppurative otitis media is an important health problem in India and timely intervention with administration of appropriate antimicrobials prevents further complications. It is an important cause of hearing loss and other serious complications which may persist lifelong in the patient, especially in children [1]. Higher prevalence (29.2\%) of CSOM was found in the first and second decades of life. This finding corroborates well with the observations made by other researchers [8-10]. Highprevalence of CSOM in children may be attributed to the fact that they are more prone to upper respiratory tract infections (URTIs). Cold weather has also been found to pre-dispose children to URTI [11, 12]. Females $(58.8 \%)$ were found to be more affected than males. This observation was found to be parallel with the findings of few authors $[13,14]$ and different from other researchers $[2,10]$.

Monomicrobial growth was found in $76.5 \%$ of the cases. There has been a variance in reporting of pure growth of single isolates from cases of CSOM and mixed growth of two or more organisms, which varies according to the geographical region and patient population.

Pseudomonas aeruginosa was found to be the most predominant organism $(49.7 \%)$ followed by Staphylococcus aureus (23.8\%). Other studies from India [2, 15], Nigeria [8], and Pakistan [13] also showed Pseudomonas as the most prevalent organism. The prevalence of different organisms varies according to the climate and geographical location. Gram negative bacilli are often found to have outnumbered the grampositive organisms in CSOM, as reported by various authors $[2,13,15]$. Fungal infections of the middle-ear are common and Candida species and Aspergillus species have been found to be the most prevalent [16]. In our study we found Candida species in 18 samples.

Antimicrobial susceptibility testing was performed for the bacterial isolates and gentamicin and amikacin were found to be susceptible for majority of the isolates (Plate 2). Ciprofloxacin showed adequate susceptibility for most of the commonly isolated organisms, both gram positive and gram negative and can be used as effective first line topical antibiotic in the treatment of CSOM. 


\section{CONCLUSIONS}

CSOM is a major cause of morbidity in developing countries like India and can be a forbearer of many complications, which can be life-changing, especially if the patient is a child. There have been changing patterns of causative organisms and antimicrobial susceptibility patterns over time due to inefficient usage of antibiotics. Timely intervention and proper treatment after culture and sensitivity testing is vital to prevent the long-term effects of CSOM.

\section{ACKNOWLEDGEMENTS}

The authors would like to thank Ms Sakuntala, Ms Sujana for their technical support and the ASRAM authorities for their kind permission to publish this article.

\section{REFERENCES}

1. Acuin, J. (2004). Global burden of disease due to chronic suppurative otitis media: Disease, deafness, deaths and DALYs Chronic Suppurative Otitis Media-Burden of Illness and Management Options. Geneva: World Health Organisation, 923.

2. Kumar, H., \& Seth, S. (2011). Bacterial and fungal study of 100 cases of chronic suppurative otitis media. J Clin Diagn Res, 5(6), 1224-7.

3. Rout, M. R., Mohanty, D., Vijaylaxmi, Y., Kamalesh, B., \& Chakradhar, M. (2012). Prevalence of cholesteatoma in chronic suppurative otitis media with central perforation. Indian Journal of Otology, 18(1), 7.

4. Berman, S. (1995). Otitis media in developing countries. Pediatrics, 96(1), 126-131.

5. Wiwanitkit, S., \& Wiwanitkit, V. (2012). Pyogenic brain abscess in Thailand. North American journal of medical sciences, 4(6), 245.

6. Morris, P. S., \& Leach, A. J. (2007). Prevention and management of chronic suppurative otitis media in aboriginal children: A practical approach. Comm Ear Hearing H, 4(6), 22-25.

7. Hassan, O., \& Adeyemi, R. E. (2007). A study of bacterial isolates in cases of otitis media in patients attending oauthc, Ile-Ife. African Journal of Clinical and Experimental Microbiology, 8(3), 130-136.
8. Osazuwa, F., Osazuwa, E., Osime, C., Igharo, E. A., Imade, P. E., Lofor, P., ... \& Dirisu, J. (2011). Etiologic agents of otitis media in Benin city, Nigeria. North American journal of medical sciences, 3(2), 95.

9. Wariso, B. A., \& Ibe, S. N. (2006). Bacteriology of chronic discharging ears in Port Harcourt, Nigeria. West African journal of medicine, 25(3), 219-222.

10. Poorey, V. K. (2002). Study of bacterial flora in CSOM and its clinical significance. Indian Journal of Otolaryngology and Head and neck surgery, 54(2), 91-95.

11. Gordon, M. A., Grunstein, E., \& Burton, W. B. (2004). The effect of the season on otitis media with effusion resolution rates in the New York Metropolitan area. International journal of pediatric otorhinolaryngology, 68(2), 191-195.

12. Rovers, M. M., Straatman, H. M. P. M., Zielhuis, G. A., Ingels, K. J. A. O., \& Van Der Wilt, G. J. (2000). Seasonal variation in the prevalence of persistent otitis media with effusion in one- yearold infants. Paediatric and perinatal epidemiology, 14(3), 268-274.

13. Mansoor, T., Musani, M. A., Khalid, G., \& Kamal, M. (2009). Pseudomonas aeruginosa in chronic suppurative otitis media: sensitivity spectrum against various antibiotics in Karachi. J Ayub Med Coll Abbottabad, 21(2), 120-3.

14. Loy, A. H. C., Tan, A. L., \& Lu, P. K. S. (2002). Microbiology of chronic suppurative otitis media in Singapore. Singapore medical journal, 43(6), 296299.

15. Shyamala, R., \& Reddy, P. S. (2012). The study of bacteriological agents of chronic suppurative otitis media-aerobic culture and evaluation. J Microbiol Biotechnol Res, 2, 152-62. Shyamala, R., \& Reddy, P. S. (2012). The study of bacteriological agents of chronic suppurative otitis media-aerobic culture and evaluation. J Microbiol Biotechnol Res, 2, 15262.

16. Ibekwe, A. O., Shareef, Z. A., \& Benayam, A. (1997). Anaerobes and fungi in chronic suppurative otitis media. Annals of Otology, Rhinology \& Laryngology, 106(8), 649-652. 